\title{
STRATEGI MEMBANGUN GLOBAL BRAND PERGURUAN TINGGI KEAGAMAAN ISLAM NEGERI (PTKIN) MENUJU WORLD CLASS UNIVERSITY
}

\author{
Siti Ma'rifatul Hasanah \\ Email : riefah.hlc@gmail.com \\ Universitas Islam Negeri Maulana Malik Ibrahim Malang
}

\begin{abstract}
Brand is a crucial element that gives great contribution to the success of an organization, both business and nonprofit organization. State Islamic Higher Education (PTKIN) needs to be aware to the value of branding and build a strong and sustainable Brand. Universitas Islam Negeri Maulana Malik Ibrahim Malang (UIN Maliki Malang) is one of PTKIN has tried several strategies to build global Brand toward world class university. This research tries to explain: 1) How strategic plan of UIN Maliki Malang Brand development towards world class university. 2) How the strategy is used by rector in building global brand toward world class university 3)How the management of international students in UIN Maliki Malang. This research uses a qualitative approach and case study type. Source of the data is derived from informants and documentation, which are adjusted to the research focus. The technique for data analysis uses interview, observation, and documentation. In analyzing the data, the researcher reduce and display the data then make the conclusion. For checking the data validity, source and method triangulation are also conducted. The results of this study indicate that: 1) UIN Maliki Malang strategic planning is formulated in University's Guideline (GBHU), which contains: that contain: integration of science and Islam, billingual, university policy, ma'had and HTQ, internationalization university, lecture and student's development, revitalization socio and religious function through LP2M, faculties development, management development, fund rising. 2) Implementation of Global branding strategy towards world class university is doing segmentation in global scala, targetting, positioning and differentiation in global scala. Segmentation changed from national, regional and international, targetting changed, positioning and differentiation promoted globally to attract international students and international reputation. 3) International student in UIN Maliki Malang was come since 2009 until now. UIN Maliki Malang has one department focused in guiding and sharing about problems and difficulties from international student. Main problem that they faced are languange (bahasa Indonesia) and academic adaptation.
\end{abstract}

Key Word: Global Branding Strategy, PTKIN, World Class University

\section{Abstrak}

Brand adalah elemen penting yang memberikan kontribusi besar terhadap kesuksesan organisasi, baik organisasi bisnis maupun nirlaba. Perguruan Tinggi Keagamaan Islam Negeri (PTKIN) perlu menyadari nilai branding dan membangun Brand yang kuat dan berkelanjutan. Universitas Islam Negeri Maulana Malik Ibrahim Malang (UIN Maliki Malang) ymerupakan salah satu PTKIN telah mencoba beberapa strategi untuk membangun Brand global menuju universitas kelas dunia. Penelitian ini mencoba menjelaskan: 1) Bagaimana rencana strategis pembangunan Brand global UIN Maulana Malik Ibrahim Malang menuju universitas kelas dunia. 2) Bagaimana strategi tersebut digunakan oleh rektor dalam membangun brand global menuju universitas kelas dunia 3) Bagaimana manajemen mahasiswa internasional di UIN Maulana Malik Ibrahim Malang. Penelitian ini menggunakan pendekatan kualitatif dan tipe studi kasus. Sumber data berasal dari informan dan dokumentasi, yang disesuaikan dengan fokus penelitian. Teknik analisis data menggunakan wawancara, observasi, dan dokumentasi. Dalam menganalisis data, peneliti mengurangi dan menampilkan data 
kemudian membuat kesimpulan. Untuk memeriksa validitas data, sumber dan triangulasi metode juga dilakukan. Hasil penelitian ini menunjukkan bahwa: 1) Perencanaan strategis UIN Maulana Malik Ibrahim Malang diformulasikan dalam Garis-garis Besar Haluan Universitas (GBHU), yang berisi: integrasi ilmu pengetahuan dan Islam, penagihan, kebijakan universitas, ma'had dan HTQ , internasionalisasi universitas, kuliah dan pengembangan siswa, revitalisasi fungsi sosial dan keagamaan melalui LP2M, pengembangan fakultas, pengembangan manajemen, peningkatan dana. 2) Implementasi strategi global branding menuju world class university adalah melakukan segmentasi dalam skala global, targetting, penentuan posisi dan differensiasi dalam skala global. Segmentasi berubah dari nasional, regional dan internasional, menargetkan perubahan, penentuan posisi dan diferensiasi yang dipromosikan secara global untuk menarik mahasiswa internasional dan reputasi internasional. 3) Mahasiswa internasional di UIN Maliki Malang datang sejak tahun 2009 hingga sekarang. UIN Maliki Malang memiliki satu departemen yang fokus dalam membimbing dan berbagi tentang masalah dan kesulitan dari mahasiswa internasional. Masalah utama yang mereka hadapi adalah bahasa (bahasa Indonesia) dan adaptasi akademik.

Kata Kunci: Strategi Branding Global, PTKIN, World Class University

\section{Pendahuluan}

Era globalisasi dan pesatnya perkembangan ekonomi dunia telah memberikan sebuah indikasi akan pentingnya peningkatan brands dan brand management. Pada abad 21, setiap pemasar organisasi bisnis membutuhkan sebuah keterampilan khusus yang sangat penting yakni kemampuan untuk mambangun dan mengelola brand (Kotler\&Amstrong, 2010). Dalam konteks bisnis, brand berfungsi sebagai aset yang tidak terlihat secara nyata tetapi memiliki nilai paling tinggi, mampu merepresentasikan esensi sebuah organisasi, sebagai pembeda yang sangat kuat (powerful differentiator) untuk sebuah organisasi dan sebagai alat untuk membuat keputusan bagi stakeholder (Aaker, 1996).

Pada era global, usaha branding tidak terbatas pada produk-produk tradisional, berbagai macam industri jasa telah mencoba menggunakan strategi branding untuk membangun brand organisasi yang lebih kuat (Marrs, 2011). Sehingga, dalam hal ini perguruan tinggi sebagai bagian dari organisasi jasa nirlaba, perlu menyadari akan pentingnya nilai branding dan adanya kebutuhan membangun brand yang kuat sekaligus sustainable. Kondisi global saat ini memberikan dampak terhadap perguruan tinggi, sehingga branding menjadi isu stretegik bagi perguruan tinggi dalam mengembangkan makna diferensiasi brand masing-masing perguruan tinggi untuk mengkomunikasikan kekuatan-kekuatan yang dimiliki (Jevons, 2006).

Isu tentang pemasaran perguruan tinggi dengan mengutamakan brand di Indonesia belum terlalu popular, akan tetapi di berbagai negara isu ini telah marak dibicarakan dan dilakukan kajian serta penelitian terkait dengan strategi membangun brand perguruan tinggi sehingga perguruan tinggi bisa berkembang, maju dan dipercaya oleh stakeholder. Sebagaimana yang dinyatakan Paul Herr (2011): "In today's higher education landscape, college and university leaders may well consider principles of brand management to assure their positions vis-à-vis their competitors. Although considerable differences between higher education and product brand exist there are sufficient similarities to warrant a foray into issues of brand management."

Implementasi branding di berbagai negara telah berkembang di sektor pendidikan dan merupakan isu yang berkembang di jenjang pendidikan tinggi. Sesuai dengan PP No. 66 tahun 2010, pendidikan tinggi adalah jenjang pendidikan pada jalur pendidikan formal setelah pendidikan menengah yang dapat berupa program pendidikan diploma, 
sarjana, magister, spesialis, dan doktor, yang diselenggarakan oleh perguruan tinggi.

Pemahaman mendalam tentang strategi membangun brand perguruan tinggi menjadi satu tahapan yang akan mengantarkan perguruan tinggi di Indonesia diakui dan bersaing secara global dan masuk ke dalam 100 besar WCU. Pemahaman dan implementasi brand perguruan tinggi secara tidak langsung juga akan meningkatkan kualitas dan kepercayaan stakeholder terhadap perguruan tinggi di Indonesia, karena sebuah brand yang kuat akan mampu menarik stakeholder untuk memilihnya dengan senang hati.

Cepatnya arus globalisasi telah membuka pemahaman baru tentang pengelolaan dunia pendidikan, salah satunya adalah membangun global brand. Salah satu dampak globalisasi adalah adanya privatisasi pendidikan dan yang berakibat pada peningkatan yang pesat dalam kompetisi dunia pendidikan, perguruan tinggi di dunia berlomba membangun brand mereka semakin sustainable dan global. Perguruan tinggi berlomba-lomba menjadikan kampusnya setara dengan IIM, IMT, Harvard, Stanford, Yale, atau yang lain (Sharma, 2007).

World Class University (WCU) menjadi salah satu topik hangat di semua negara. World class university menjadi topik yang banyak didiskusikan dalam forum-forum ilmiah, berbagai penelitian baik di dalam maupun luar negeri membahas tentang WCU, berbagai publikasi ilmiah maupun artikel-artikel terkait dengan world class university, misalnya World Class Education (for Whom) oleh Susan L. Robertson (2017), The Features of World Class Universities oleh Hsiou-Hsia-Tai (2017), The demand for 'world-class universities': What is driving the race to the top? Oleh Marguerite Rigoglioso(2017); dan banyak artikel dan penelitian yang membahas, mengkritik, dan mencari pendekatan-pendekatan baru untuk membangun perguruan tinggi menjadi bagian dari WCU.

World Class University merupakan persaingan dan ranking universitas terbaik di dunia, baik versi The Times Higher Education Supplement (THES), Academic Ranking of World Universities (ARWU) maupun Webometrics. Masuk dalam kategori World Class University merupakan satu kebanggaan dan prestige bagi perguruan tinggi (Litle Circle Foundation, 2015). Di Indonesia sendiri, belum ada kampus yang masuk dalam 500 besar World Class Universitiy (WCU), baik versi THES, ARWU maupun Webometrics (Sakti Nasution, 2016). Bahkan Universitas Indonesia (UI) dan Universitas Gadjah Mada (UGM) masih menempati peringkat di atas 800. Berbagai upaya telah dilakukan untuk masuk dalam 100 besar dalam rangkin universitas, namun Indonesia masih berada di atas angka 800 dalam skala internasional dan di atas 180 untuk skala Asia (Times Higher Education, 2017).

Berdasarkan data di atas, maka penelitian ini menjadi penting dilakukan, yaitu untuk mencari formulasi strategi terbaik untuk pengembnagan perguruan tinggi, baik PTAIN, PTN maupun PTS. PTAIN, sebagai wahana pengembangan pendidikan tinggi, pernah mengalami masa perkembangan yang menggembirakan, yakni pada tahun 1960an, mahasiswa yang belajar di PTAIN mengalami kenaikan pesat, bahkan datang dari Negara Malaysia, Brunai Darussalam, dan Singapura. Ke depan, diharapkan PTAIN kembali bangkit dan lebih maju dan berkualitas serta mampu bersaing secara regional dan global.

Penelitian ini mengambil situs di UIN Maulana Malik Ibrahim Malang, salah satu dari Perguruan Tinggi Agama Islam Negeri (PTAIN) yang sebelumnya berstatus sebagai Sekolah Tinggi Agama Islam Negeri (STAIN). Lompatan perubahan dari STAIN menjadi UIN dan perkembangan yang pesat serta keberhasilan membangun reputasi kampus menjadi hal yang menarik untuk diteliti (Siti Ma'rifatul Hasanah, 2012). Upaya untuk go-public baik skala regional maupun internasional terus dilakukan. Upaya untuk membangun global brand terus dilakukan, dan hal ini mengalami pertumbuhan yang cepat dalam mengenalkan positioning universitas di tingkat internasional. 
Fokus penelitian ini adalah: 1) Bagaimana Perencanaan Strategis dalam Membangun Global Brand menuju World Class University di UIN Maulana Malik Ibrahim Malang? 2) Bagaimana Model Pengembangan dan Implementasi Global Brand sebagai upaya menuju World Class University di UIN Maulana Malik Ibrahim Malang? 3) Bagaimana Pola pendampingan mahasiswa internasional di UIN Maulana Malik Ibrahim Malang?

\section{Metode Penelitian}

Penelitian ini menggunakan metode kualitatif, yang mana peneliti mengumpulkan data dengan cara bertatap muka langsung dan berinteraksi dengan orang-orang di tempat penelitian. Penelitian kualitatif adalah jenis penelitian yang temuannya tidak diperoleh melalui prosedur statistik (Straus dan Corbin dalam Syamsuddin dan Vismaia, 2007). Penelitian kualitatif lebih memperhatikan pada pembentukan teori substantif berdasarkan konsep-konsep yang timbul dari data empiris. Dalam penelitian kualitatif peneliti merasa tidak tahu tentang apa yang tidak diketahui, sehingga desain yang dikembangkan selalu merupakan kemungkinan yang terbuka akan berbagai perubahan yang diperlukan dan fleksibel terhadap kondisi yang ada di lapangan pengamatannya (Nurul Zuriah, 2005). Penelitian ini tentang strategi membangun global brand sebagai upaya menuju World Class University di PTKIN.

Penelitian ini dilakukan di Universitas Islam Negeri Maulana Malik Ibrahim (UIN Maliki) Malang yang terletak di Jl. Gajayana 50 Malang. UIN Maliki Malang berdiri berdasarkan Surat Keputusan Presiden No. 50 tanggal 21 Juni 2004. Sebelum bernama UIN Maulana Malik Ibrahim Malang, kampus ini mengalami beberapa kali perubahan status dan pergantian nama. Sejarah singkat perubahan status tersebut dimulai dari pendirian Fakultas Tarbiyah cabang IAIN Surabaya pada tahun 1961.

Terdapat beberapa teknik dalam pengumpulan data, tetapi yang lebih sering dipakai dalam studi kasus adalah observasi, wawancara, dan analisis dokumentasi (Syamsudin dan Vismaia, 2007). Lebih rinci prosedur pengumpulan data adalah: a) wawancara mendalam dan terbuka, b) Observasi langsung, c). Penelaahan terhadap dokumen tertulis.

Data dianalisis setelah dikumpulkan dan dituangkan dalam bentuk laporan lapangan. Tujuan analisis data ialah untuk mengungkapkan: a) data apa yang masih perlu dicari, b) hipotesis apa yang perlu diuji, c) pertanyaan apa yang perlu dijawab, d) metode apa yang harus digunakan untuk mendapatkan informasi baru, dan e) kesalahan apa yang harus segera diperbaiki. Ada berbagai cara untuk menganalisis data, tetapi secara garis besarnya dengan langkah-langkah sebagai berikut: (a) reduksi data, (b) display data, (c) pengambilan kesimpulan dan verifikasi (Husaini Usman dan Purnomo S. Akbar, 2006).

Pengecekan keabsahan data merupakan konsep penting yang bertujuan untuk menjamin dan meyakinkan pihak lain, bahwa temuan penelitian benar-benar absah. Dalam penelitian ini peneliti menggunakan metode triangulasi. Triangulasi adalah pendekatan multimetode yang dilakukan peneliti pada saat mengumpulkan dan menganalisis data. Ada 4 macam triangulasi yang digunakan sebagai teknik pemeriksaan yang memanfaatkan penggunaan sumber, metode, antar peneliti, dan teori. Dalam penelitian ini, triangulasi sumber data dan triangulasi metode. Triangulasi sumber data adalah menggali kebenaran informai tertentu melalui berbagai metode dan sumber perolehan data. Triangulasi metode dilakukan dengan cara membandingkan informasi atau data dengan cara yang berbeda(Rahardjo).

\section{Hasil Penelitian dan Analisis}

\section{Rencana Strategis UIN Maulana Malik Ibrahim Malang Dalam Membangun Global Brand Menuju World Class University}

Rencana Strategis UIN Maulana Malik Ibrahim Malang menjadi alasan fundamental pengembangan kelembagaan untuk diorientasikan menjadi kampus 
internasional. Sesuai dengan renstra UIN Maulana Malik Ibrahim Malang jangka panjang 25 Tahun ke Depan (2006-2030). Bertujuan untuk lebih mengarahkan program universitas dalam rangka peningkatan mutu, relevansi, dan daya saing di tengah percaturan global. Renstra tersebut merupakan kelanjutan dan pengembangan dari Renstra yang telah dibuat sebelumnya, yakni Renstra Pengembangan STAIN Malang 10 Tahun ke depan. Renstra sebelumnya dipandang telah berhasil mengantarkan kampus ini berubah statusnya menjadi Universitas Islam Negeri (UIN) Malang sehingga mendapat perhatian dari lembaga keuangan internasional, Islamic Development Bank (IDB) berupa bantuan pembangunan kampus yang sangat megah.

Rencana strategis (Renstra) UIN Maliki Malang selama 25 tahun, dibagi menjadi 3 tahap, yaitu: tahap pertama (2006-2010): Fokus pada kemantapan kelembagaan (institutional establishment) dan penguatan akademik (academic reinforcement). Dalam jangka menengah (2011-2020) untuk mencapai posisi universitas agar lebih dikenal dan diakui di tingkat regional (Regional Recognition and Reputation); dan dalam jangka panjang (2021-2030) untuk mencapai posisi puncak universitas, yakni agar lebih dikenal dan diakui di tingkat internasional (International Recognition and Reputation)( M. In'am Esha, 2014).

World Class University, menjadi isu sentral yang dibahas banyak lembaga pendidikan. Bukan hanya di Indonesia, tetapi juga di luar negeri. Arah pengembangan UIN Maulana Malik Ibrahim Malang disesuaikan dengan indikator-indikator Times Higher Education Supplement (THES), yaitu meliputi 5 unsur utama, yaitu pengajaran (teaching), penelitian (research), sitasi (citation), pendapatan industri (industry income), serta pandangan internasional (international outlook). Dengan bobot masing-masing:

- Pengajaran (teaching) $\quad: 30 \%$

- Penelitian (research) $\quad: 30 \%$

- Sitasi (citation) : $\quad 30 \%$
- Pandangan internasional (International outlook) : 7,5\%

- Pendapatan industri (industry income) $\quad: 2,5 \%$

Pengembangan kampus secara berkala berusaha untuk memperbaiki dan meningkatkan 5 aspek tersebut. Adapun dalam renstra UIN Maulana Malik Ibrahim Malang, terdapat sembilan (9) bidang yang menjadi fokus pengembangan, meliputi: pendidikan dan pengajaran, penelitian dan penerbitan, pengabdian pada masyarakat, ketenagaan, kemahasiswaan, kelembagaan, kerjasama, prasarana dan sarana, dan keuangan.

\section{Strategi Membangun Global Brand UIN Maulana Malik Ibrahim Malang menuju World Class University}

Penelitian ini memotret langkahlangkah strategis UIN Maulana Malik Ibrahim Malang dalam membangun global brand, dianalisis menggunakan teori STPDB Hermawan Kartajaya. Rangkaian strategi yang telah dan sedang dilaksanakan di UIN Maliki Malang merupakan satu hal yang bersifat kasuistik, dan apa yang dilaksanakan mayoritas memiliki dasar dan dalil agama yang sangat kuat, sehingga seringkali bukan dimaksudkan semata-mata sebagai usaha marketing lembaga, tetapi lebih bersifat syiar dan peningkatan kualitas. Analisis ini peneliti harapkan tidak mengurangi makna jihad dan syiar yang diniatkan sejak awal.

a. Segmentasi

Sesuai dengan Renstra 25 tahun UIN Maliki Malang, yang bertujuan menjadi The center of excellence and Islamic Civilization. UIN membagi dalam tiga tahap, bersamaan dengan perluasan pengenalan kampus. Dalam tahap pertama, UIN Maliki mentargetkan kokohnya sistem akademik, dalam hal ini sasaran yang dibidik adalah skala nasional dan terus memperbaiki akademik kampus. Pada tahap kedua, tahun 2011-2020 adalah tahap pengenalan kampus ke wilayah regional. Dalam hal ini terdapat perluasan segmen, perluasan pasar yang ingin dimasuki. Jika sebelumnya nasional, pada tahap dua kemudian memasuki tingkat regional, dan 
pada tahun 2021-2030 memasuki segmen internasional.

Perubahan segmentasi menuntut perubahan kultur dan sistem untuk kemudian menyesuaikan dengan kebutuhan segmen pasar yang ingin dicapai. Untuk menjadi kampus internasional misalnya, UIN Maliki Malang tidak bisa tetap menjadi STAIN dengan jurusan terbatas atau IAIN yang memiliki jurusan serumpun. Perubahan segmen ini menuntut perubahan banyak hal, dianatranya adalah perubahan kelembagaan dan sistem akademik kampus.

Perubahan status kelembagaan dalam perspektif marketing memiliki konsep yang sama dengan perluasan segmen pasar dan penambahan produk. Dalam marketing mix, ada beberapa elemen pemasaran yang salah satunya adalah segmentasi. Segmentasi adalah cara melihat pasar dengan cara yang unik. Hermawan Kartajaya mengungkapkan bahwa untuk membangun brand image yang kuat, salah satu hal yang perlu diperhatikan adalah segmentasi. Segmentasi merupakan elemen pemasaran strategis yang harus dilakukan organisasi secara tepat, karena akan berhubungan dengan elemen-elemen pemasaran yang lain. Supaya bisa beroperasi secara efektif, organisasi pertama perlu menetapkan misinya atau "reason for being". Dalam misi tersebut, organisasi perlu memahami "Organisasi bergerak di bidang apa?". Setelah menetapkan misi serta pasarnya, maka perlu membagi pasar menjadi segmen-segmen yang lebih kecil berdasarkan karakteristik serupa dari perilaku stakeholder, dan kemudian menentukan segmen mana yang akan dilayani (Kotler, 2003).

Adapun sesuai dengan Renstra UIN Maliki Malang, maka segmen pasar yang dituju mengalami perkembangan. Rencana strategis (Renstra) UIN Maliki Malang selama 25 tahun, dibagi menjadi 3 tahap, yaitu: tahap pertama (2006-2010): Fokus pada kemantapan kelembagaan (institutional establishment) dan penguatan akademik (academic reinforcement). Dalam jangka menengah
(2011-2020) untuk mencapai posisi universitas agar lebih dikenal dan diakui di tingkat regional (Regional Recognition and Reputation); dan dalam jangka panjang (2021-2030) untuk mencapai posisi puncak universitas, yakni agar lebih dikenal dan diakui di tingkat internasional (International Recognition and Reputation) (M. In'am Esha, 2014).

Berdasarkan renstra 25 tahun tersebut, maka segmen pasar UIN Maliki Malang meluas, dari nasional, regional dan internasional. Hal ini tidak cukup hanya dengan memperluas pasar saja, tetapi serangkaian strategi terkait dengan perluasan pasar, meliputi pemahaman terhadap perilaku pelanggan, karakteristiknya dan melihat pasar secara kreatif.

b. Targetting

Targeting adalah proses mengevaluasi seberapa menariknya tiaptiap segmen market dan memilih satu atau beberapa segmen untuk dimasuki (Kotler, 2010). Dalam hal ini UIN Maliki Malang memilih target market sesuai dengan kesiapan SDM yang dimiliki. Dan untuk menguatkan segmen market yang dipilih, UIN Maliki selalu meningkatkan kualitas SDM yang dimiliki, yaitu dengan cara memberikan kesempatan studi lanjut kepada para dosen dan karyawan. Serta penambahan sarana fisik dan non fisik.

Pengembangan pada bidang kelembagaan merupakan bagian dari strategi segmentasi dan targeting. Yaitu melihat pasar PTAIN yang sangat terbatas pada jurusan-jurusan keagamaan an sich, dengan target mahasiswa yang ingin belajar di bidang tersebut, maka jumlah pasar yang bisa dilayani sangat terbatas. Dengan adanya pengembangan kelembagaan, maka pasar yang dilayani juga semakin banyak. Penambahan fakultas merupakan strategi segmentasi, yaitu melihat pasar dengan cara yang berbeda dari yang dilakukan pesaing. Dalam hal ini UIN Maliki Malang melihat bahwa segmen pasar yang bisa dilayani tidak sebatas jurusan keagamaan saja, melainkan bisa menambah di segmen yang lain. Hal ini secara otomatis juga mempengaruhi targeting yang ditetapkan. 
Segmentasi dan targeting yang ditetapkan UIN Maliki Malang mengalami perubahan sesuai dengan renstra universitas. Yaitu pada tahun 2005-2010 memantapkan stabilitas akademik dan kelembagaan di tingkat nasional, sehingga target mahasiswa yang dibidik adalah mahasiswa berskala nasional. Memasuki tahun 2011-2020 tujuan yang diharapkan adalah pengakuan dan reputasi di tingkat regional, peletakan fondasi menuju tahap tersebut telah dilakukan seperti diperolehnya Akreditasi Institusi dari Badan Akreditasi Nasional Perguruan Tinggi (BAN-PT) dengan Akreditasi B (UIN Malang, 2010). Pada tahun ini target mahasiswa adalah tingkat regional. Sedangkan tahun 2021-2030, sesuai dengan roadmap pengembangan yang dicanangkan, universitas berkomitmen untuk mencapai pengakuan dan reputasi internasional. Sehingga target mahasiswa yang diharapkan juga mahasiswa dalam tingkat internasional. Pemeroleh sertifikat ISO 9001:2008 pada tanggal 22 Januari 2011, yang diserahkan oleh Solichin A. Darmawan selaku Certification Manager PT SGS Jakarta (Gema, 2011).

c. Positioning

Positioning adalah janji (Hermayan Kertajaya, 2005). Sebuah tindakan untuk mendesain penawaran dan citra organisasi sehingga organisasi dapat berada di posisi kompetitif yang bermakna dan berada di benak stakeholder. Definisi lain menyebutkan bahwa positioning adalah sebuah proses untuk menempatkan organisasi di benak stakeholder. Definisi tersebut memiliki arti bahwa organisasi harus memiliki kredibilitas agar positioning organisasi dapat mudah melekat di benak stakeholder (Kotler dan Keller, 2009).

Positioning menyangkut bagaimana membangun kepercayaan, keyakinan, dan kompetensi di mata stakeholder. Bila unsur tersebut dimiliki, maka organisasi memiliki "keberadaan" (being) di benak stakeholder. Karena itu, positioning disebut dengan "being strategy". Positioning adalah mengenai bagaimana lembaga pendidikan mendapat kepercayaan stakeholder untuk dengan sukarela memilih organisasi tersebut.

d. Differensiasi

Diferensiasi secara umum memiliki pengertian bagaimana menciptakan penawaran organisasi yang berbeda dibanding pesaing. Philip Kotler(2009) mendefinisikan diferensiasi sebagai pembedaan penawaran pasar suatu organisasi untuk menciptakan nilai stakeholder yang unggul. Sedangkan Hermawan Kartajaya mendefinisikan diferensiasi sebagai proses mengintegrasikan konten, konteks, dan infrastruktur dari apa yang ditawarkan kepada stakeholder. Proses mengintegrasikan dilakukan melalui proses penciptaan tawaran yang unik dengan berkonsentrasinpada dimensi, content (what to offer), context (how to offer), dan infrastruktur (enabler) (MIM Academy, 2010).

Tarbiyah ulul albab merupakan konsep yang menjadi acuan oleh semua komponen yang terlibat di UIN Maliki Malang. Konsep ini menyangkut dasar filosofis, arah dan kualitas yang ingin diraih, kualitas proses dan produk yang diidealkan, karakteristik serta berbagai pendukung yang diperlukan. Konsep tarbiyah ulul albab ini diharapkan mampu melahirkan generasi ulul albab, yaitu orang-orang yang mengedepankan dzikir, fikir dan amal shalih. Memiliki ilmu yang luas, pandangan mata yang tajam, otak yang cerdas hati yang lembut dan semangat serta jiwa pejuang dengan sebenar-benar perjuangan.

Konsep tarbiyah ulul albab dan integrasi universitas ma'had ini merupakan bagian dari diferensiasi. Diferensiasi adalah menciptakan penawaran yang berbeda ke stakeholders untuk menciptakan nilai yang unggul dibanding pesaing (Kotler dan Keller, 2006 dan MIM Academy, 2010). Hermawan Kartajaya mendefinisikan diferensiasi sebagai proses mengintegrasikan konten, konteks dan infrastruktur dari apa yang ditawarkan kepada stakeholders (Hermawan Kartajaya, 2005). 
Konsep tarbiyah ulul albab dan integrasi ma'had universitas merupakan bagian dari konteks yang ditawarkan kepada stakeholders. Yaitu suatu cara bagaimana konten atau isi yang ditawarkan kepada stakeholders bisa dicapai. Context (how to offer), merupakan dimensi diferensiasi yang menunjuk pada cara lembaga untuk menawarkan value kepada stakeholders. Hal ini merupakan bagian intangible dari diferensiasi karena berupa cara penawaran value kepada pelanggan yang berbeda dari pesaing.

Program penunjang merupakan bentuk diferensiasi, yaitu masuk dalam content yang ditawarkan kepada stakeholders. Strategi membuat program penunjang merupakan strategi diferensiasi yang bertujuan membuat pembeda dengan lembaga lain dan mendukung positioning. Positioning UIN Maliki Malang, yaitu melahirkan ulama'- intelek yang professional dan/atau intelek-profesional yang ulama' Cara mewujudkannya aalah dengan adanya diferensiasi yang solid.

e. Brand

Sebuah organisasi harus memikirkan mereknya sebagai: (1) produk, (2) organisasi, (3) orang, dan (4) simbol. Perspektif-perspektif ini berbedabeda, namun tujuannya adalah untuk mengklarifikasi, memperkaya, dan mendiferensiasi identitas merek tersebut. Identitas merek (brand identity) dapat memberikan arahan, tujuan, dan makna dari merek itu sendiri. Asosiasi merek merepresentasikan untuk apa menyiratkan sebuah janji organisasi terhadap stakeholder.

Strategi yang diimplementasikan di UIN Maulana Malik Ibrahim Malang, jika dianalisis menggunakan teori ST-PDB, maka terdapat keserasian antara teori dengan implementasi. Dengan adanya perluasan segmentasi, targetting, positioning dan differensiasi maka UIN Malang berusaha mengkomunikasikan identitas lembaga secara internasional. Membangun global brand dalam hal ini, setelah melalui wawancara, observasi dan dokumentasi maka peneliti dalam hal ini menarik satu kesimpulan bahwa membangun global brand adalah dengan melakukan segmentasi, targetting, positioning dan differensiasi secara global, sehingga brand yang terbentuk menjadi global brand.

Adapun upaya menuju world class university (WCU), terus diupayakan melalui berbagai macam cara. Diantaranya dengan memenuhi kriteria penilaian THES, maupun upaya-upaya lain. Sinergi dari berbagai elemen kampus untuk memperbaiki lembaga, baik secara struktur, strategi, pelayanan dan berbagai hal lain. Dalam bidang akademik misalnya, UIN Maliki menyediakan 1 Milyar lebih dana untuk program percepatan guru besar, yang mana tahun 2017 UIN Maliki masih memiliki 6 guru besar. Ke depan, target guru besar ada di masing-masing jurusan, artinya masing-masing jurusan memiliki guru besar (Sambutan rektor dalam acara pengukuhan guru besar Prof. Dr. Asmaun Sahlan, M.Ag). Selain itu perbaikan berkala kurikulum dan pelayanan akademik juga menjadi prioritas kampus.

Prof. Caroline McMillen, dkk mengadaptasi pemikiran Jamil Salmi, merumuskan tantangan untuk membangun World Class University sebagai berikut:

1) Strong leadership

2) Bold vision of the institution's missions and goals

3) Objective assessment of strengths and new areas for improvement

4) Set new stretch goals

5) Clearly articulated strategic plan to translate the vision into concrete targets and programs

6) Design and implement a renewal plan than can lead to improved performance

Berdasarkan rumusan Jamil Salmi dan Caroline McMillen tersebut, maka apa yang dilakukan UIN Maliki Malang, dalam membangun global brand menuju world class university masih perlu ditingkatkan dalam beberapa aspek. Secara Umum Prof. Caroline McMillen memberikan sebuah framework tentang membangun kampus menuju World Class University sebagai berikut: 
Gambar 1

WCU framework (Prof. Caroline McMillen, dkk)

Secara umum, strategi menuju kampus WCU ini juga akan mengantarkan universitas memiliki brand global. Sehingga ada kaitan erat yang tidak bisa dan beberapa aspek lain yang berkaitan dengan strategi bersaing universitas di tingkat global.

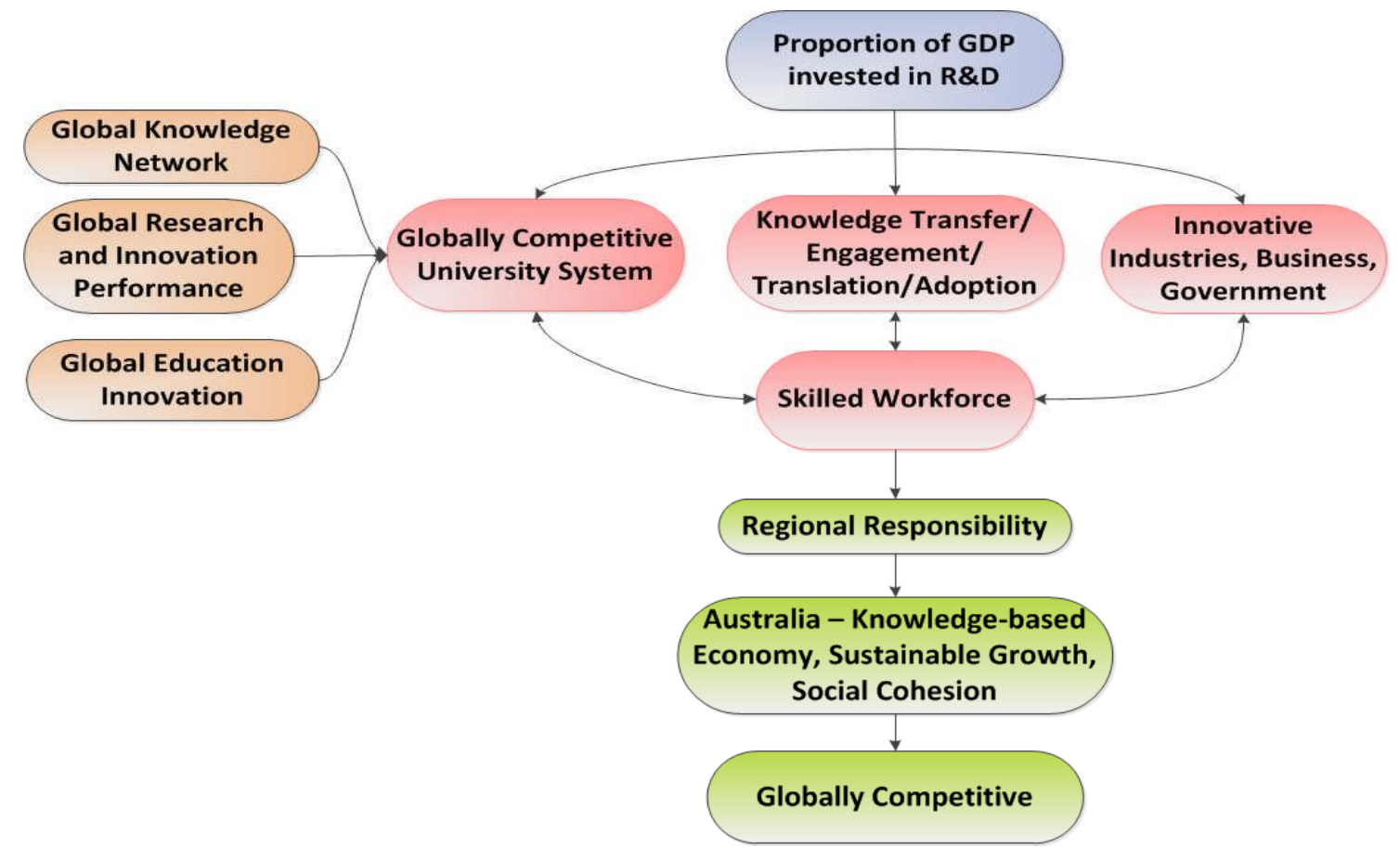

lepas, antara membangun global brand menjadi WCU dan upaya menjadi WCU dan memiliki global brand. Apa yang tersebut di framework adalah adaptasi dari New Castle University, namun demikian meski strategi membangun brand bersifat kasuistik, namun selalu ada hal-hal yang bersifat general. Seperti framework di atas. Untuk mencapai global competitive, terlebih dahulu universitas harus menyiapkan kerjasama akademik secara global, riset global, inovasi pendidikan secara global, memiliki bisnis, industri yang innovatif., memiliki alumni yang terbekali dengan ketrampilan yang memadai untuk bersaing di dunia kerja,

\section{Pendampingan Mahasiswa Asing di UIN Maliki Malang}

Berdasarkan data pada hasil penelitian tentang mahasiswa asing di UIN Maulana Malik Ibrahim Malang, dimana mahasiswa asing di UIN Maliki datang dari berbagai negara, maka renstra UIN Maliki pada tahap kedua, yaitu regional recognition telah berhasil dilaksanakan. Berdasarkan data asal negara mahasiswa asing ini, maka pengenalan UIN Maliki tidak hanya di kawasan regional, namun perlu ada peningkatan jumlah dan negaranegara Barat yang menjadi fokus UIN Maliki ke depan, menjelang renstra tahap 3. 
Tabel 1

Data Asal Negara Mahasiswa Luar Negeri/Asing

\begin{tabular}{|c|c|c|c|c|c|c|c|}
\hline \multirow[t]{2}{*}{ No. } & \multirow[t]{2}{*}{ Negara } & \multicolumn{6}{|c|}{ Tahun Akademik } \\
\hline & & 2013 & 2014 & 2015 & 2016 & 2017 & TOTAL \\
\hline 1. & Afghanistan & 3 & - & - & 1 & - & 4 \\
\hline 2. & Albania & 1 & - & - & - & - & 1 \\
\hline 3. & China & - & - & - & 2 & 7 & 9 \\
\hline 4. & Italia & 1 & - & - & - & - & 1 \\
\hline 5. & Kamboja & 8 & & 1 & & 2 & 3 \\
\hline 6. & Libya & 35 & 55 & 10 & 6 & 1 & 107 \\
\hline 7. & Madagaskar & - & - & - & - & - & - \\
\hline 8. & Malaysia & 1 & 10 & 30 & 16 & 2 & 59 \\
\hline 9. & Rusia & 1 & - & - & 2 & - & 3 \\
\hline 10. & Singapura & - & - & - & - & - & - \\
\hline 11. & Sudan & 6 & 1 & 2 & 3 & 15 & 27 \\
\hline 12. & Somalia & - & 7 & 5 & - & - & 12 \\
\hline 13. & Timor Leste & - & 5 & - & 1 & - & 6 \\
\hline 14. & Pakistan & - & 1 & - & - & - & 1 \\
\hline 15. & Philipina & - & - & - & 1 & - & 1 \\
\hline 16. & Jerman & - & 1 & - & - & - & 1 \\
\hline 17. & Yaman & - & - & - & 2 & - & 2 \\
\hline 18. & Arab Saudi & 1 & 1 & 1 & - & 1 & 4 \\
\hline 19. & Brunei Darussalam & - & - & 1 & - & - & 1 \\
\hline 20. & Slovakia & - & 1 & - & - & - & 1 \\
\hline 21. & Thailand & 11 & 20 & 13 & 10 & 3 & 57 \\
\hline
\end{tabular}

Berdasarkan tabel asal negara di atas, terdapat penurunan jumlah mahasiswa dari masing-masing negara pada tahun 2017, kecuali mahasiswa dari Sudan yang mengalami peningkatan signifikan, dari 2016 berjumlah 3, pada tahun 2017 menjadi 15. Sedangkan negara-negara yang lain semua mengalami penutrunan. Dari hasil wawancara mahasiswa menyampaikan bahwa UIN Maliki memiliki sistem akademik yang telah bagus, namun kendala bahasa dan adaptasi belajar yang kadangkala kurang mendapat perhatian dari masing-masing dosen pengampu mata kuliah.

Berikut akan kami tampilkan data sebaran mahasiswa asing dari masing-masing fakultas dan jurusan, peningkatan dan penurunan ahasiswa dari masing-masing jurusan bisa menjadi perhatian bersama. apakah tingkat kepuasan layanan akademik di kelas, jurusan dan fakultas yang menjadi faktor penyebabnya, atau faktor lain yang mengakibatkan penurunana atau peningkatan. 
Tabel 2

DATA SEBARAN PROGRAM STUDI MAHASISWA LUAR NEGERI/ASING

\begin{tabular}{|c|c|c|c|c|c|c|c|c|}
\hline \multirow{3}{*}{ Kode } & \multirow{3}{*}{ Fakultas/Jurusan } & \multicolumn{7}{|c|}{ Jumlah Mahasiswa Asing } \\
\hline & & \multicolumn{5}{|c|}{ Tahun Akademik } & \multirow{2}{*}{$\begin{array}{l}\text { Jumlah } \\
\text { Tiap } \\
\text { Prodi }\end{array}$} & \multirow{2}{*}{$\begin{array}{c}\text { Jumlah } \\
\text { Tiap } \\
\text { Fakultas }\end{array}$} \\
\hline & & 2013 & 2014 & 2015 & 2016 & 2017 & & \\
\hline F.01 & Fakultas Ilmu Tarbiyah dan Keguruan & & & & & & & 22 \\
\hline 11 & Pendidikan Agama Islam & 6 & 5 & 2 & 1 & - & 14 & \\
\hline 13 & Pendidikan Ilmu Pengetahuan Sosial & - & - & - & - & - & - & \\
\hline 14 & Pendidikan Guru Madrasah Ibtidaiyah & - & - & - & - & - & - & \\
\hline 15 & Pendidikan Bahasa Arab & 1 & - & 1 & 2 & 3 & 7 & \\
\hline 16 & Pendidikan Guru Raudlatul Athfal & - & - & - & - & - & - & \\
\hline 17 & Manajemen Pendidikan Islam & - & - & - & 1 & - & 1 & \\
\hline F.02 & Fakultas Syariah & & & & & & & 60 \\
\hline 21 & Al-Ahwal Al-Syakhsiyah & - & 13 & 21 & 14 & 1 & 49 & \\
\hline 22 & Hukum Bisnis Syariah & - & 1 & 9 & 1 & - & 11 & \\
\hline 23 & Hukum Tata Negara & - & - & - & - & - & - & \\
\hline 24 & Ilmu Alquran dan tafsir & - & - & - & - & - & - & \\
\hline F.03 & Fakultas Humaniora & & & & & & & 25 \\
\hline 31 & Bahasa dan Sastra Arab & - & 2 & 2 & 1 & 4 & 9 & \\
\hline 32 & Bahasa dan Sastra Inggris & 1 & 5 & 4 & 2 & 4 & 16 & \\
\hline F.04 & Fakultas Psikologi & & & & & & & 5 \\
\hline 41 & Psikologi & - & 2 & - & 2 & 1 & 5 & \\
\hline F.05 & Fakultas Ekonomi & & & & & & & 22 \\
\hline 51 & Manajemen & 3 & 3 & 1 & 5 & 1 & 13 & \\
\hline 52 & Akuntansi & 1 & - & 1 & 1 & 1 & 4 & \\
\hline 53 & Diploma Tiga (DIII) perbankan Syari'ah & - & - & - & - & - & - & \\
\hline 54 & Perbankan Syariah & - & - & 1 & 4 & - & 5 & \\
\hline F.06 & Fakultas Sains dan Teknologi & & & & & & & 42 \\
\hline 61 & Matematika & - & - & - & - & - & - & \\
\hline 62 & Biologi & - & - & - & - & - & - & \\
\hline 63 & Kimia & - & 1 & - & - & - & 1 & \\
\hline 64 & Fisika & - & - & - & - & - & - & \\
\hline 65 & Teknik Informatika & 8 & 6 & 12 & 1 & - & 27 & \\
\hline 66 & Teknik Arsitektur & 4 & 8 & - & 1 & 1 & 14 & \\
\hline F.06 & $\begin{array}{l}\text { Fakultas Kedokteran dan Ilmu-Ilmu } \\
\text { Kesehatan }\end{array}$ & & & & & & & 40 \\
\hline 91 & Pendidikan Dokter & - & - & - & - & - & - & \\
\hline 92 & Profesi Dokter & - & - & - & - & - & - & \\
\hline 93 & Farmasi & 9 & 4 & 5 & 6 & 16 & 40 & \\
\hline F.07 & Pascasarjana & & & & & & & 98 \\
\hline 71 & Magister Manajemen Pendidikan Islam & 5 & 14 & 1 & - & - & 20 & \\
\hline 72 & Magister Pendidikan Bahasa Arab & 1 & - & - & 1 & 1 & 3 & \\
\hline 73 & Doktor Manajemen Pendidikan Islam & 8 & 17 & - & - & - & 25 & \\
\hline 74 & Doktor Pendidikan Bahasa Arab & - & 1 & - & 1 & - & 2 & \\
\hline 75 & Magister Studi Ilmu Agama Islam & 15 & 7 & 1 & - & - & 23 & \\
\hline 76 & $\begin{array}{l}\text { Magister Pendidikan Guru Madrasah } \\
\text { Ibtidaiyah }\end{array}$ & - & - & - & - & - & & \\
\hline 77 & Magister Pendidikan Agama Islam & - & - & 1 & - & - & 1 & \\
\hline 78 & Magister Al-Ahwal Al-Syakhsiyah & 7 & 4 & - & - & - & 11 & \\
\hline 79 & $\begin{array}{l}\text { Doktor Pendidikan Agama Islam } \\
\text { Berbasis Studi Interdisipliner }\end{array}$ & - & 3 & 1 & 1 & - & 5 & \\
\hline 80 & Magister Ekonomi Syariah & - & 7 & & 1 & - & 8 & \\
\hline & TOTAL & 69 & 104 & 63 & 46 & 33 & 315 & 315 \\
\hline
\end{tabular}


Berdasarkan data sebaran mahasiswa masing-masing jurusan dan fakultas terdapat banyak penurunan di beberapa jurusan dan fakultas. Hal ini mengindikasikan bahwa perlu dilakukan kajian ulang terkait dengan penyebab menurunnya jumlah mahasiswa asing tersebut. Apakah karena faktor internal, seperti layanan akademik atau karena besaran biaya SPP mahasiswa asing yang akhir-akhir ini beberapa kampus memberikan biaya lebih ringan bahkan beasiswa full selama studi di kampus tersebut.

Keberadaan mahasiswa asing di sebuah lembaga atau perguruan tinggi yang sedang menuju World Class University sangat penting, karena terdapat indikator international outlook yang salah satunya adalah keberadaan mahasiswa asing di kampus tersebut. Kerjasama yang telah terjalin dengan beberapa negara yang mengirimkan mahasiswanya untuk belajar di UIN Maliki Malang harus tetap terjalin dngan, pembentukan ikatan alumni UIN Maliki Malang secara internasional akan membantu memberikan informasi bagi mahasiswa baru atau calon mahasiswa yang akan mendaftar di UIN Maliki Malang, sekaligus sebagai sarana promosi UIN Maliki dalam skala internasional.

\section{Kesimpulan}

Berdasarkan hasil penelitian dan analsisis, maka dapat kami simpulkan bahwa:

1. World Class University, menjadi isu sentral yang dibahas banyak lembaga pendidikan. Bukan hanya di Indonesia, tetapi juga di luar negeri. Arah pengembangan UIN Maulana Malik Ibrahim Malang disesuaikan dengan GBHU (Garis-garis Besar Haluan Universitas). Jika dianalisis sesungguhnya GBHU mengandung 5 unsur indikator penilaian disesuaikan dengan indikator-indikator Times Higher Education Supplement (THES), yaitu meliputi 5 unsur utama, yaitu pengajaran (teaching), penelitian (research), sitasi (citation), pendapatan industri (industry income), serta pandangan internasional (international outlook).

2. Strategi yang diimplementasikan di UIN Maulana Malik Ibrahim Malang, jika dianalisis menggunakan teori STPDB, maka terdapat keserasian antara teori dengan implementasi. Dengan adanya perluasan segmentasi, targetting, positioning dan differensiasi maka UIN Malang berusaha mengkomunikasikan identitas lembaga secara internasional. Membangun global brand dalam hal ini, setelah melalui wawancara, observasi dan dokumentasi maka peneliti dalam hal ini menarik satu kesimpulan bahwa membangun global brand adalah dengan melakukan segmentasi, targetting, positioning dan differensiasi secara global, sehingga brand yang terbentuk menjadi global brand. Adapun upaya menuju wordl class university (WCU), terus diupayakan melalui berbagai macam cara. Diantaranya dengan memenuhi kriteria penilaian THES, maupun upaya-upaya lain. Sinergi dari berbagai elemen kampus untuk memperbaiki lembaga, baik secara struktur, strategi, pelayanan dan berbagai hal lain. Secara umum, strategi menuju kampus WCU ini juga akan mengantarkan universitas memiliki brand global. Sehingga ada kaitan erat yang tidak bisa lepas, antara membangun global brand menjadi WCU dan upaya menjadi WCU dan memiliki global brand. Strategi membangun brand bersifat kasuistik, namun selalu ada hal-hal yang bersifat general. Seperti framework di atas. Untuk mencapai global competitive, terlebih dahulu universitas harus menyiapkan kerjasama akademik secara global, riset global, inovasi pendidikan secara global, memiliki bisnis, industri yang innovatif., memiliki alumni yang terbekali dengan ketrampilan yang memadai untuk bersaing di dunia kerja, dan beberapa aspek lain yang berkaitan dengan strategi bersaing universitas di tingkat global. 
3. Berdasarkan data pada hasil penelitian tentang mahasiswa asing di UIN Maulana Malik Ibrahim Malang, dimana mahasiswa asing di UIN Maliki datang dari berbagai negara, maka renstra UIN Maliki pada tahap kedua, yaitu regional recognition telah berhasil dilaksanakan. Berdasarkan data asal negara mahasiswa asing ini, maka pengenalan UIN Maliki tidak hanya di kawasan regional, namun perlu ada peningkatan jumlah dan negara-negara Barat yang menjadi fokus UIN Maliki ke depan, menjelang renstra tahap 3 . Adapun untuk respon mahasiswa asing yang belajar di UIN Maliki Malang terhadap pelayanan akademik, fasilitas belajar, ma'had, dan lingkungan dapat disimpulkan bahwa mereka cukup puas. Terkait dengan masalah yang dihadapi, ada dua ranah, yaitu mahasiswa baru bahasa Indonesia mereka belum lancar sedangkan di kelas mereka harus belajar dengan buku dan penjelasan dosen yang semuanya menggunakan bahasa Indonesia, sehingga menjadi masalah yang berkelanjutan karena materi satu dengan yang lain saling terkait. Selain kendala bahasa, proses adaptasi mahasiswa seringkali belum difahami oleh dosen pengampu mata kuliah. Kultur belajar yang ada di Indonesia dengan negara mereka biasanya jauh berbeda, dan untuk beradaptasi mahasiswa memerlukan waktu, sehingga pemahaman dosen mata kuliah akan sangat membantu untuk mencapai tujuan pembelajaran dan menciptakan kenyamanan belajar.

\section{Daftar Pustaka}

Aarons, Mark De Swan dan Frank van Den Driest. 2010. The Global Brand CEO; Building the Ultimate Marketing Machine. New York: Airstream.

Al-Qur'an dan Terjemahnya, 2005, Depag RI

Alma, Buchari dan Hurriyati, Ratih (Ed). 2008. Manajemen Corporate \& Strategi Pemasaran Jasa Pendidikan. Bandung: Alfabeta,
Aaker, David A. 1996. Building Strong Brands. New York: Free Press

Arikunto, Suharsimi. 2006. Prosedur Penelitian, suatu pendekatan, Bandung: Rosdakarya.

Cybermatic. Top Universities Indonesia 2016-2017. (diakses melalui http://www.cybermaticuniversity. com, pada 23 Februari 2017)

Fajar, Malik. 2004. Proses Perubahan STAIN menjadi UIN Malang. Malang: UIN Malang Press.

Hasanah, Siti Ma'rifatul. 2012. Strategi Membangun Brand Image PTAIN (Studi di UIN Maulana Malik Ibrahim Malang, Pascasarjana UIN Mailiki Malang, Tesis, Tidak diterbitkan

Herr, Paul. Higher Education Institutional Brand Value in Transition: Measurement and Management Issues. (Diakses melalui http://net.educause.edu/ir/library .com. pada 26 Maret 2011)

Hollis, Nigel. The Global Brand: How to Create and develop Lasting Brand Value in The World Market, Palgrave MacMillan Publisher.

Kartajaya, Hermawan. 2000. Marketing Plus; Siasat Memenangkan Persaingan Global, Jakarta: Gramedia Pustaka Utama,

Kartajaya, Hermawan. 2004. On Brand, Bandung: Mizan

Kartajaya, Hermawan. 2005. Positioning, Diferensiasi, Brand, Jakarta: Gramedia Pustaka Utama.

Kotler dan Keller. 2009. Manajemen Pemasaran edisi 12 jilid 1, penerjemah: Benyamin Mollan. Jakarta: PT. Macana Jaya Cemerlang

Kotler, Philip, dkk. 2005. Rethinking Marketing, Jakarta: Indeks

Marrs, Rachel, Musa, Utilizing Brand Audit to Develop University Brand: A Case Study, Journal ASBBS Annual Converence: Las Vegas, Vol. 18 No. 1, February 2011.

McMillan, Caroline, The Future Workforce in Building World Class University, Asutralia: New Castle University. 
Moleong, Lexy. 2005, Metode Penelitian Kualitatif, Bandung: Rosdakarya,

Robertson, Susan L. World Class Higher Education (for Whom), Online articles, published by the Centre for Globalisation, Education and Societies, University of Bristol, Bristol BS8 1JA, UK. http://susanleerobertson.com/pgu blications/ (diakses pada 23 Februari 2017)

Sadat, Andi. 2009. Brand Belief, Jakarta: Salemba Empat.

Salmi, Jamil. 2009. The Challanges of Establishing World Class University. World Bank

Sri Wahyudi, Agustinus. 1996. Manajemen Strategik, Jakarta: Binarupa Aksara.
Sugiyono. 2009. Metode Penelitian Kuantitatif, Kualitatif dan $R \& D$, Bandung: Alfabeta.

Suprayogo, Imam. Pertemuan Rektor UIN, IAIN, dan PTAI. (diakses melalui http://www.uinmalang.ac.id 02 Maret 2011)

The Offical MIM Academy Coursebook. 2010. Brand Operation. Jakarta: Esensi.

Tjiptono, Fandy. 2005. Brand Management \& Strategy. Yogyakarta: Andi.

Webometric. Top Universities Indonesia 2016-2017. (Diakses melalui http://www.rankinguniversitiewe bometrics.2011.com. pada 23 Februari 2017) 